\title{
El cisma en la iglesia metodista pentecostal de Chile. Una interpretación
}

\author{
Fernando Salas Moncada ${ }^{1}$
}

\begin{abstract}
Resumen
Este artículo considera la tesis del cisma o ruptura como elemento fundamental en la historia del cristianismo evangélico de Chile, especialmente en la Iglesia Metodista Pentecostal como ejemplo paradigmático. Explora acerca de las causas y razones de dicha constante y analiza sus consecuencias y los desafíos que presenta para el mundo evangélico pentecostal chileno.
\end{abstract}

Palabras clave: Evangélicos, Pentecostalismo, Protestantismo, Cisma.

\begin{abstract}
This article considers the thesis of schism or break as a fundamental element in the history of the evangelical cristianism in Chile, especially in the Metodist Pentecostal Church as a paradigmatic example. Explores about the causes and reasons of this constant and analizes his consequences and challenges that presents for the Chilean pentecostal evangelical world.
\end{abstract}

Key words: Evangelicals, Pentecostalism, Protestantism, Schism.

1 Chileno, Egresado de Derecho de la Universidad de Chile. Email: fsalasmon@yahoo. com; Fono: 8-2135060. 
El cisma en la iglesia metodista pentecostal de Chile. Una interpretación - Fernando Salas Moncada

"Os digo, pues, ahora: desentendeos de estos hombres y dejadlos. Porque si esta idea o esta obra es de los hombres, se destruirá; pero si es de Dios, no conseguiréis destruirles. No sea que os encontréis luchando contra Dios". Gamaliel, Doctor de la Ley (Hechos de los Apóstoles; Cap. 5, Vers. 38 y 39, Biblia de Jerusalén).

"Se produjo entonces una tirantez tal que acabaron por separarse el uno del otro: Bernabé tomó consigo a Marcos y se embarcó rumbo a Chipre; por su parte Pablo eligió por compañero a Silas y partió, encomendado por los hermanos a la gracia de Dios" (Hechos de los Apóstoles; Cap. 15, Vers. 39 y 40, Biblia de Jerusalén).

\section{Algunas consideraciones previas}

En el 2009 se cumplirán 100 años de presencia de cristianismo evangélico pentecostal en Chile. Su congregación más antigua, numerosa y la más conocida de todas, la Iglesia Metodista Pentecostal, atraviesa por un profundo y grave conflicto, que ad portas de ese centenario la presenta dividida, confirmando a nuestro juicio, una dolorosa constante de separaciones y rupturas que conforme al relato bíblico antes mencionado incluso estaría presente en los inicios del cristianismo apostólico.

\section{Historia y contexto constitucional}

La presencia del Protestantismo en Chile se remonta al siglo XIX y se vincula básicamente a las comunidades de inmigrantes (ingleses, norteamericanos y alemanes) que profesaron su fe de manera privada y que progresivamente fueron sumando convertidos de origen nacional al amparo de los esfuerzos misioneros de anglicanos, luteranos, presbiterianos, metodistas y bautistas. Los nombres de James Thompson, Joseph Lancaster, Thomas Kendall, John Rowlandson, William Armstrong, Allen Francis Gardiner, Charles Sadlier, Henry L. Weiss, Albert Dawson, Ira La Fetra, y sobresalientemente David Trumbull, William Taylor y Juan Bau- 
tista Canut de Bon, dan cuenta de esos educadores, misioneros, pastores y predicadores, que inspirados por un celo evangelizador, sobrellevaron discriminaciones, persecución y prejuicios, en un país que no era el de sus orígenes y cuya sociedad era tremendamente conservadora en materia religiosa. ${ }^{2}$

La opinión mayoritaria y categórica de la Iglesia dominante de la época era de rechazo a cualquier intento de secularizar la sociedad, de separar a la Iglesia del Estado, y de permitir la expresión pública de cualquier otra fe. El reconocimiento de la Libertad Religiosa como un valor fundamental llegará por parte de Roma sólo en la segunda mitad del siglo XX en el Concilio Vaticano II con la Declaración Dignitatis Humanae. "Todos los hombres deben estar inmunes de coacción, tanto por parte de personas particulares, como por parte de grupos sociales y de cualquier potestad humana, y esto de tal manera que en lo religioso ni se obligue a nadie a actuar contra su conciencia, ni se le impida que actúe conforme a ella en privado y en público, sólo o asociado con otros, dentro de los límites debidos. Declara además que el derecho a la libertad religiosa está realmente fundado en la dignidad misma de la persona humana, tal como se conoce por la palabra de Dios revelada y por la misma razón natural". ${ }^{3}$

La consagración legal en Chile recién culminará en 1999 con la promulgación de la Ley 19.638 sobre Constitución Jurídica de las Iglesias y Organizaciones religiosas. Antes de aquello, hubo una larga historia de reformas legales y constitucionales que se materializaron gracias a la unión de sectores protestantes, liberales y laicos. ${ }^{4}$

2 Para una Historia del Protestantismo en Chile durante el siglo XIX, ver: Vergara, Ignacio (1968). El Protestantismo en Chile, Santiago, Editorial del Pacífico. Una completa revisión se encuentra en: Sepúlveda, Juan, (1999). De Peregrinos a Ciudadanos. Breve Historia del Cristianismo Evangélico en Chile, Santiago, Fundación Konrad Adenauer y Facultad Evangélica de Teología. Ver también: Canut de Bon L. Alejandro, (1996). Juan Bautista Canut de Bon. El Pastor que dejó un nombre, Santiago, Platero Libros.

3 Ver Declaración Dignitatis Humanae sobre la Libertad Religiosa, en Vaticano II Documentos Conciliares Completos (1967). Madrid, Editorial Razón y Fe.

4 Para revisar las relaciones Iglesia Estado, ver: Pacheco Gómez, Máximo, (2004). La separación de la Iglesia y el Estado en Chile y la diplomacia vaticana, Santiago, Editorial Andrés Bello. Ver también: Precht Pizarro, Jorge, (2001). Derecho Eclesiástico del Estado 
El cisma en la iglesia metodista pentecostal de Chile. Una interpretación - Fernando Salas Moncada

La Constitución de 1833 en su artículo $5^{\circ}$ establecía que la religión oficial de la República de Chile era la Católica Apostólica y Romana, con exclusión del ejercicio público de cualquier otra. En 1865 se introdujo una ley interpretativa a dicho artículo, aprobándose el siguiente proyecto de ley:

"Artículo $1^{\circ}$. Se declara que por el artículo $5^{\circ}$ de la Constitución se permite a los que no profesan la religión católica, apostólica romana, el culto que se practica dentro del recinto de capillas o edificios de propiedad particular.

Artículo $2^{\circ}$. Es permitido a los disidentes fundar y sostener escuelas privadas para la enseñanza de sus propios hijos en la doctrina de sus religiones" (Pacheco Gómez, 2004: pág. 277).

En el decenio de 1880 se promulgarán un conjunto de leyes que marcarán un avance en materia de separar la influencia de la Iglesia Católica en la sociedad; son las denominadas Leyes Laicas: de Cementerios, Matrimonio Civil y de Registro Civil. Resulta ilustrativo, a fin de graficar el debate ideológico en el parlamento, reproducir las palabras de uno de los paladines del liberalismo y de la causa secular de la época, don Enrique MacIver: "La idea de secularizar nuestras instituciones, de introducir lo que podríamos llamar el laicismo en nuestras instituciones civiles, políticas y sociales, no es una idea nacida de esta o aquella causa accidental. Es una idea general, una aspiración que tiene profundas raíces en el país y hasta una necesidad. Los que nos sentamos en estos bancos sostenemos como parte esencial de nuestro programa político esta reforma, no por antipatía a la religión misma, sino por la intima convicción de que es altamente necesaria la secularización del Estado. Queremos llegar al ideal de que en las naciones de origen latino se ha formulado por medio del conocido aforismo: la Iglesia libre en un Estado libre" (Campos Harriet, 1983: pág. 402).

de Chile, Análisis Históricos y Doctrinales, Santiago, Ediciones Universidad Católica de Chile. Del mismo autor: Precht Pizarro, Jorge, (2006). 15 Estudios sobre Libertad Religiosa en Chile, Santiago, Ediciones Universidad Católica de Chile. 
La separación del Estado se producirá con la promulgación de la Constitución de 1925, después de largas negociaciones con la Iglesia Católica. El texto constitucional en su art. 10 N² señaló: "La Constitución asegura: la manifestación de todas las creencias, la libertad de conciencia y el ejercicio libre de todos los cultos que no se opongan a la moral, a las buenas costumbres o al orden público, pudiendo por tanto, las diversas confesiones religiosas, erigir y conservar templos y sus dependencias con las condiciones de seguridad e higiene fijadas por las leyes y ordenanzas.

El libre ejercicio de los cultos puede realizarse en las calles o en los templos; $y$ los lugares destinados al objeto deben cumplir con las leyes civiles y ordenanzas destinadas a garantizar la seguridad de los fieles y la observancia de los principios de higiene pública.

La Iglesia, las confesiones e instituciones religiosas de cualquier culto tendrán los derechos que otorgan y reconocen con respecto a los bienes, las leyes actualmente en vigencia; pero quedarán sometidas al derecho común, dentro de las garantías de esta Constitución, para el ejercicio de sus bienes futuros.

Los templos y sus dependencias destinados al servicio de un culto religioso estarán exentos de contribuciones" (Precht Pizarro, 2001: págs.102-103).

La separación del Estado acarreaba para la Iglesia una pérdida de recursos importante para su financiamiento, que desde 1853 se imputaba con cargo al presupuesto de la nación. Es así que una disposición transitoria de la nueva Constitución incorporaba la compensación económica exigida como condición de la negociación por parte de la Iglesia. La disposición primera transitoria señalaba: "Durante cinco años el Estado entregará al señor Arzobispo de Santiago la cantidad de dos millones quinientos mil pesos anuales para que se inviertan en el país en las necesidades del culto de la Iglesia Católica" (Precht Pizarro, 2001: pág. 98).

La Constitución de 1980 actualmente en vigor, reproduce en su artículo 19 N6 lo señalado por la Constitución de 1925. Fi- 
El cisma en la iglesia metodista pentecostal de Chile. Una interpretación - Fernando Salas Moncada

nalmente, el marco regulatorio general se completa como ya se señaló con la Ley 19.638 de 1999 y sus reglamentos complementarios. $^{5}$

La lucha por el reconocimiento del Estado de un estatuto igualitario para todas las confesiones religiosas se extendió por más de 150 años en la historia republicana de Chile. Fue un largo y conflictuado proceso y que durante el siglo XX tuvo como un actor principal al protestantismo pentecostal autóctono.

\section{El nacimiento de una iglesia}

"iMirad, hermanos, quiénes habéis sido llamados! No hay muchos sabios según la carne ni muchos poderosos ni muchos de la nobleza. Ha escogido Dios más bien lo necio del mundo, para confundir a los sabios. $Y$ ha escogido Dios lo débil del mundo, para confundir lo fuerte. Lo plebeyo y despreciable del mundo ha escogido Dios; lo que no es, para reducir a la nada lo que es" (Pablo, Primera Epístola a los Corintios. Cap. I, Vers. 26. Biblia de Jerusalén).

El fenómeno de los avivamientos pentecostales dentro de las iglesias protestantes tradicionales, se produce en forma relativamente simultánea a principios del siglo XX. Existe consenso en los historiadores en atribuir el comienzo masivo del fenómeno a la Misión de la calle Azusa en Los Angeles, USA, en 1906, pastoreada por William Seymour, discípulo a su vez de Charles Fox Parham en Topeka, Kansas. Pronto, una nueva vivencia de las Sagradas Escrituras y la experiencia de los "dones" sobrenaturales del Espíritu Santo se difuminaron por todo los EEUU, Europa, Asia, África y América. ${ }^{6}$

5 Para una completa revisión de la legislación nacional e internacional sobre Libertad Religiosa, ver: Normas Fundamentales sobre la Libertad de Cultos, 2004, Santiago, Instituto Chileno de Estudios Humanísticos. También: Ley de Culto y documentos complementarios, 1999, Santiago, Instituto Chileno de Estudios Humanísticos y Fundación Konrad Adenauer.

6 Para una completísima historia del movimiento pentecostal a nivel mundial, ver: Synan, Vinson, (2006). El siglo del Espiritu Santo, cien años de renuevo pentecostal y carismático, Buenos Aires, Editorial Peniel. 
La doctrina del "bautismo del Espíritu Santo", tal cual acaeció en la Iglesia Apostólica primitiva el día de Pentecostés en Jerusalén, y su manifestación sobrenatural a través de los carismas o dones como el hablar en lenguas o glosolalia, danzas extáticas, don de profecía e interpretación de sueños, sanidad divina mediante la oración e imposición de manos, expulsión de demonios, serían sus características externas más visibles.

Desde el inicio del movimiento su expansión estuvo vinculada a los sectores más postergados económica y culturalmente, siendo factor de descrédito y prejuicio: "Desde el principio la gran mayoría de los líderes y los seguidores del mensaje pentecostal provinieron de las clases trabajadoras más bajas. Una de las principales acusaciones dirigidas a los adherentes del Pentecostés moderno, era que eran analfabetos, incultos, y tal falta de refinamiento era considerada una prueba de su necedad e ingenuidad" (Synan, 2006: Pág. 72).

La discriminación, prejuicio y persecución acompañaron el mensaje de los primeros pentecostales en todo el mundo. Como toda organización humana, el movimiento experimentó también escándalos, situaciones de fraude, excesos y separaciones. No obstante, transcurridos 100 años, los movimientos pentecostales representan el más vigoroso y visible crecimiento del mundo cristiano en general. En palabras del eminente historiador del pentecostalismo, Vinson Synan, "el número de pentecostales, que solamente eran un puñado de personas en 1901, creció de manera estable hasta convertirse en la familia de protestantes más grande del mundo para comienzos del siglo XXI. Con más de doscientos millones de miembros de denominaciones pentecostales, este grupo sobrepasó a las iglesias ortodoxas para convertirse en la segunda familia denominacional cristiana, sólo superada por la Iglesia Católica.

Además de los pentecostales de estas denominaciones clásicas, hay millones de carismáticos en iglesias de las denominaciones históricas e iglesias no denominacionales, tanto católicas como protestantes. El número total llega ahora a más de quinientos millones de personas. Este 
El cisma en la iglesia metodista pentecostal de Chile. Una interpretación - Fernando Salas Moncada

crecimiento ha hecho que algunos historiadores hablen del siglo XX como "el siglo pentecostal" (Synan, 2006: Pág. 12).

\section{Pentecostales chilenos}

"Por un año, derretidos por los calores, helados por los fríos y sacudidos por los vientos, pudimos adorar a Dios en ese tabernáculo" Willis C. Hoover.

El relato más importante de los acontecimientos del Pentecostés autóctono fue hecho por el misionero norteamericano Willis C. Hoover en su tradicional libro "Historia del Avivamiento Pentecostal", recientemente reeditado en inglés y español por su nieto, quien compartió en su niñez y adolescencia con su abuelo, y conoció personalmente a la mayoría de los líderes históricos de las principales ramas del mundo pentecostal chileno, por lo que constituye un documento histórico muy importante. ${ }^{7}$

Se ha establecido la "conexión India" de los hechos acaecidos en Chile a través del intercambio epistolar que sostuvieron la esposa de Hoover y la misionera norteamericana Minnie Abrams, quienes se habían conocido en Chicago cuando se preparaban para las misiones. Miss Abrams era colaboradora en India de Pandita Ramabai, que a su vez había participado en Inglaterra en rogativas para el derramamiento del Espíritu Santo en India (Sepúlveda, 1999: Pág. 93).

Estas cartas y folletos hablaban de un bautismo del Espíritu Santo, como suceso diferente a la justificación y santificación. El pastor Hoover encabezaba la Iglesia Metodista Episcopal en Valparaíso y junto a su congregación iniciaron la búsqueda a través del estudio, ayuno y oración de estas nuevas experiencias espirituales que estimularon su fe. "En conexión con las cartas y la literatura nos empeñamos en estudiar las escrituras y en orar más.

7 Hoover G., Mario (2000). History of the Pentecostal Revival in Chile, Willis Collins Hoover, Santiago, Imprenta Eben-Ezer; Hoover G., Mario (2002). El Movimiento Pentecostal en Chile del Siglo XX, Santiago, Imprenta Eben-Ezer. 
Así llegamos a convencernos que había profundidades de experiencia cristiana que no habíamos alcanzado; y se despertó en nosotros una viva hambre de poseer todo lo que Dios tenía para nosotros" (Hoover, 2002: Pág. 19).

Las manifestaciones que siguieron tanto en Valparaíso como en Santiago, reproducen los fenómenos pentecostales comentados anteriormente "...el avivamiento desde su principio fue acompañado por manifestaciones extraordinarias de diversas clases -risas, lloro, gritos, cantos, lenguas extrañas, visiones, éxtasis en las que las personas caían al suelo y se sentían trasladadas a otra parte al cielo, al Paraíso, a campos hermosos, con experiencias variadas- hablaban con el Señor, con ángeles, o con el diablo" (Hoover, 2002: Pág. 41).

Estupor, desconcierto, escándalo, confusión y rechazo por parte de la jerarquía metodista local, prepararon el terreno para la escisión y separación definitiva e irreversible del movimiento pentecostal del protestantismo histórico y de carácter misionero. Este se materializó en la Conferencia Anual del metodismo que se celebró en Valparaíso en 1910. Contra Hoover se formularon dos cargos: Primero, enseñanza y diseminación de doctrinas falsas y antimetodistas, pública y privadamente. Segundo, conducta gravemente imprudente (Hoover, 2002: Pág. 69).

La resolución de la Conferencia fue contundente: "Por cuanto ciertas doctrinas falsas tales como la enseñanza que el bautismo del Espíritu Santo es acompañado por el don de lenguas, visiones, milagros de sanidad y otras manifestaciones, han sido diseminadas en varias partes de esta Conferencia y representadas como las doctrinas de la Iglesia Metodista Episcopal; nosotros por la presente declaramos que aquellas doctrinas son anti-metodistas, contrarias a las Escrituras e irracionales y nuestros miembros están avisados que no deben aceptarlas como enseñanzas de nuestra Iglesia" (Hoover, 2002: Pág. 71).

Las diferencias insalvables entre Hoover, sus seguidores y la jerarquía de la Iglesia Metodista Episcopal, derivaron en la renuncia del pastor norteamericano a su posición y a la perte- 
El cisma en la iglesia metodista pentecostal de Chile. Una interpretación - Fernando Salas Moncada

nencia a dicha iglesia. Adicionalmente, dos grupos disidentes de Santiago se unirían a los de Valparaíso, en la separación del tronco metodista episcopal. Se trataba del grupo de congregados en torno a la Primera Iglesia Metodista Episcopal de Santiago, conocida como Iglesia de Jotabeche, y del grupo de la Segunda Iglesia Metodista Episcopal de Santiago, que se transformaría en la Iglesia de calle Sargento Aldea. A petición de los miembros de estos grupos, aceptó Hoover liderarlos y formar con ellos la Iglesia Metodista Pentecostal de Chile. He aquí el cisma originario que da nacimiento al pentecostalismo chileno.

\section{Las separaciones. Poder y carisma}

De acuerdo al Diccionario de la Real Academia Española, el vocablo cisma (del latín schisma), significa división o separación en el seno de una iglesia o religión. Pues la historia del Pentecostalismo chileno y en particular la historia de la Iglesia Metodista Pentecostal es la historia de las separaciones y divisiones. Así sucedió desde el origen en 1909, y se repitió en 1933, en los años 1945-1946 y acontece ahora en el 2007. La afirmación de Christian Lalive D’Epinay en su clásico estudio de los años sesenta parece, entonces, tener plena vigencia: "El cisma es una constante de la historia del pentecostalismo chileno". 8

En nuestra opinión, el elemento común denominador en estas separaciones es la búsqueda del mayor grado de dominio y control de la organización, especialmente de su esfera financiera, por parte de los líderes más o menos carismáticos en pugna. En buenas cuentas, más que diferencias teológicas o doctrinarias, se trataba y se trata del viejo cuento del Poder.

Ya lo señalaba Hoover en el cisma originario, en cartas dirigidas tanto al Obispo General de la Iglesia Metodista Episcopal, como al Secretario de la Sociedad Misionera de dicha congrega-

8 Lalive D’Epinay, Christian (1968). El Refugio de las Masas. Estudio Sociológico del Protestantismo Chileno, Santiago, Editorial del Pacífico, Pág. 124. 
ción, que su renuncia y las diferencias de juicio irreconciliables, obedecían a la ausencia de "...libertad de acción que es esencial para el buen éxito de la obra" y que los que propugnaban su salida no tenían a la vista argumentos de tipo doctrinario, sino que actuaban coludidos bajo otros intereses: “. ..y ellos están obrando bajo autoridad, y no por convicción. La evidencia está en que estaban tan prontos para votar de eliminar los cargos, como de hacerlos, porque otra persona se los dijo". No hay discrepancias fundamentales con el fundador del Metodismo y así lo señala: "Estudiaré y enseñaré a Wesley y la Biblia. No tengo doctrinas nuevas" (Hoover, 2002: Págs. 85 y 88).

Juan Sepúlveda complementa la interpretación anterior agregando elementos de carácter sociocultural y señalando dos aspectos básicos para entender el cisma: "El conflicto entre una religiosidad centrada en la objetividad del dogma, en la cual la fe consiste en la aceptación formal, consciente y racional de determinadas creencias y doctrinas, y una religiosidad que da primacía a la experiencia subjetiva de Dios, en la que la fe es una respuesta a una especie de posesión del ser por lo divino. El conflicto entre una religión mediatizada por especialistas de las clases cultas (un clero ilustrado) y una religión en la que el pueblo sencillo, pobre, tiene acceso directo a Dios y en que tal relación puede comunicarse con el lenguaje de los sentimientos y de la propia cultura" (Sepúlveda, 1999: Págs. 98-99).

Lalive D'Epinay ya había hablado de un conflicto de mentalidades, oponiendo a una mentalidad religiosa racionalizante (jerarquía eclesiástica de clase media dominada por el extranjero), una mentalidad religiosa mística (creyentes nacionales de clase popular).

Una reciente investigación ha caracterizado como fuego y nieve respectivamente, al carisma pentecostal con su espontaneidad y emocionalismo por una parte, y a la religión metodista tradicional, burocrática y racional, por la otra. Estos dos elementos como cualidades adscritas a una y otra parte se separarían en el cisma originario de 1909: "Y así, cual fuego y nieve quedaron 
El cisma en la iglesia metodista pentecostal de Chile. Una interpretación - Fernando Salas Moncada

rotos todos los vínculos entre el Metodismo y el naciente movimiento pentecostal". 9

A medida que el movimiento crecía y se desarrollaba, gracias al ímpetu evangelizador de sus fieles, su compromiso activo con sus congregaciones y también a las condiciones sociopolíticas (separación de la Iglesia y el Estado, crisis económica, desplazamientos de población del campo a la ciudad, entre otros factores), surgirían nuevos liderazgos que comenzarían a disputar los espacios de influencia y poder en la naciente organización.

Hacia el año 1933 se produce el primer cisma dentro de la ya constituida Iglesia Metodista Pentecostal de Chile. Un verdadero punch o golpe de estado afectará a su líder originario, el venerable Mister Hoover.

El pastor Hoover a esa fecha detentaba el cargo de Superintendente General del movimiento y habían transcurrido más de veinte años del inicio del movimiento. Seguía dirigiéndolo con mano firme, y en opinión de muchos autoritaria, como por ejemplo en materia de prácticas cúlticas como la introducción de otros instrumentos musicales dentro de la liturgia pentecostal más allá del tradicional órgano.

Los estudiosos del período coinciden en atribuir a una combinación de factores el conflicto que deviene en ruptura de la joven iglesia. Entre ellos el nacionalismo imperante dentro del movimiento, que ya no quería a un misionero extranjero a la cabeza de la organización, acusaciones de inmoralidad en contra de Hoover y al surgimiento de un nuevo fuerte liderazgo representado por el pastor Manuel Umaña, que encabezaba la iglesia de Jotabeche en Santiago. Esta iglesia, junto a las de Valparaíso y Concepción se irían transformando en las más poderosas en el ámbito nacional. Luis Orellana nos entrega una clave para entender la acumulación de poder, desde las opacas prácticas administrativas y financieras,

9 Orellana, U., Luis (2006). El Fuego y la Nieve. Historia del Movimiento Pentecostal en Chile: 1909-1932. Tomo I, Concepción, CEEP Ediciones. 
especialmente en la gestión de los diezmos y la posesión legal de los bienes de la iglesia: "Hacia 1930, las Iglesias de Valparaíso, Santiago y Concepción, por el alto número de sus miembros, eran ya lo suficientemente solventes para cubrir los gastos básicos de la Iglesia como para sustentar dignamente a sus pastores, estableciéndose claras diferencias económicas con los pastores de las Iglesias del resto del país. Durante este período, se institucionalizó la práctica de que las Iglesias locales se mantuvieran con sus propios recursos. Sin lugar a duda, allí se habituó a los fieles a que los diezmos debían ser un donativo directo para el Pastor y que se entregaba en forma personal, reconociendo así su autoridad y liderazgo. Esto creó lazos afectivos entre el fiel y sus pastores, como a su vez el compromiso de apoyo económico al trabajo de la Iglesia local. Con el tiempo esta práctica pasó a ser un requisito previo para ser Oficial, predicador o jefe de un grupo y por ende factor clave en el sostén propio de las Iglesias. Sin embargo, más tarde esto generó pugnas y conflictos de intereses; acrecentó las diferencias socioeconómicas entre los pastores y agudizó las políticas eclesiásticas poco claras, las que provocaron profundos quiebres institucionales" (Orellana, 2006; Págs. 125-126).

Un crucial aspecto que sólo se regularizará con la dictación de la Ley 19.638 en 1999 y que incumbe a aquellas iglesias pentecostales que pretenden un reconocimiento como persona jurídica de derecho público, es el que dice relación con la inscripción legal de las propiedades a nombre de las respectivas corporaciones y no a título particular o privado como tradicionalmente sucedía por largos años. Aspecto que contribuía a confundir los patrimonios personales e institucionales y generar como consecuencia prácticas de corrupción. El templo emblemático de Jotabeche fue adquirido y registrado en 1927 a nombre de Manuel Umaña, y sólo en 1947 se transfirió a nombre de la Iglesia Metodista Pentecostal, en circunstancias que ésta ya gozaba de reconocimiento jurídico como corporación de derecho privado desde 1929 (Orellana, 2006; Pág.129).

En relación con las acusaciones de inmoralidad en contra de Hoover, hay discrepancia entre los autores. Por ejemplo, Lalive 
El cisma en la iglesia metodista pentecostal de Chile. Una interpretación - Fernando Salas Moncada

D'Epinay al comentar los sucesos del quiebre señala: "En los años 30, la Iglesia Metodista Pentecostal, estaba aún gobernada por el iniciador del movimiento, el pastor Hoover, espléndida figura patriarcal de imponente barba. Un grupo aprovechó la ola de nacionalismo que se desataba sobre Chile, para tratar de eliminar a este último sobreviviente de los tiempos misioneros. La lucha fue ardua y sucia, y las armas empleadas -calumnias, insinuaciones sobre la vida privada, tentativas para hacer expulsar a Hoover de Chile-, no sirven para honrar a los protagonistas. No se trataba ya de buscar un consenso; y como los adversarios de Hoover lograron tener una mayoría, lo expulsaron a él y a los ocho pastores que lo defendían. Estos últimos, seguidos por gran parte de los fieles de sus congregaciones respectivas, fundaron la Iglesia Evangélica Pentecostal en 1932" (Lalive D’Epinay, 1968: Pág. 125).

Similar posición, aunque interesada y benevolente por provenir de su nieto, formula Mario Hoover. Es interesante reproducir en sus propias palabras lo acontecido: "Mi abuelo era un extranjero, un gringo, a la cabeza de una iglesia nueva nacional. El espiritu nacionalista, que prevalecía en la sociedad, se había filtrado y manifestado con regularidad desde el principio. Como nuevos líderes aparecían, con fuertes personalidades, el nacionalismo llegó a ser el factor principal del esfuerzo de sacar a Willis Collins Hoover de la superintendencia. Además, sus contrarios pensaban que su edad ya estaba muy avanzada para este cargo tan importante.

Para muchos, mi abuelo parecía ser un autócrata muy inflexible en cuestiones del diario vivir para un cristiano. Sus estrictas tradiciones Wesleyanas de lo que es bueno y malo lo tropezaba con la cultura latina, fácil y sin complicaciones. Puede que mi abuelo haya sido muy rígido y puritano. Por ejemplo, él no toleraba que los hermanos se entremezclaran en deportes. Como se ha dicho antes, él se oponía al teatro y otras diversiones mundanales como el baile y la victrola. Definitivamente no permitía el uso de la guitarra en la iglesia, no importando todo lo escrito en el Salmo 150. Estaba opuesto a la guitarra debido a la marcada identificación con la cueca, siempre acompañada de tomateras y parrandas. El estándar y las prácticas contemporáneas de los '30probablemente pe- 
saban en contra de estas restricciones. Pero en esa época mi abuelo las vio como distracciones que prevenían la misión principal de la iglesia de ganar almas para el Señor. Aun antes de 1933, un líder de gran energía se levantaba para usurpar la posición de superintendente de la Iglesia Metodista Pentecostal" (Hoover, 2002: Pág. 236-237).

El líder a que hace alusión Mario Hoover es Manuel Umaña, quien encabezaría la oposición a su abuelo. Mario Hoover señala que su abuelo mantuvo una moralidad personal absoluta delante de la Iglesia desde el principio de su ministerio en Chile hasta el fin de su vida. Sin embargo, la evidencia reunida por otros investigadores, da base de credibilidad a las acusaciones de inmoralidad. En todo caso esta acusación habría sido usada como una herramienta al servicio de la lucha de poder (Sepúlveda, 1999: Pág. 103, citando a Kessler).

Hoover junto a sus fieles seguidores es expulsado de la Iglesia que fundó y se organiza en torno a la Iglesia Evangélica Pentecostal, primera rama escindida del movimiento autóctono.

\section{Otra vez el poder}

En 1930 Enrique Chávez era secretario de Manuel Umaña. A principios de los 40 fue enviado a Curicó a establecer una nueva iglesia de la corporación. Se trataba de una persona muy cercana a Umaña y dotado de grandes condiciones de oratoria, liderazgo y organización. Ya hemos señalado la falta de transparencia y fiscalización de los crecientes recursos que ingresaban a las arcas de la Iglesia. Sólo bastaba que surgiera una nueva personalidad fuerte al interior de la organización y que cuestionara dichas prácticas para que el conflicto se produjera; esa personalidad fue Enrique Chávez. La situación se complejizó a raíz de una grave enfermedad del superintendente Umaña en el sentido que alimentó suspicacias respecto a la sucesión en el cargo. Chávez junto a cuatro pastores cuestionaron la ausencia de una tesorería general en la Iglesia y un mecanismo claro respecto de la sucesión en el cargo de superintendente. Los intentos de reforma culminaron con la 
El cisma en la iglesia metodista pentecostal de Chile. Una interpretación - Fernando Salas Moncada

expulsión de los disidentes y éstos fundaron la Iglesia Pentecostal de Chile entre los años 1944 y 1945, con Chávez a la cabeza como su flamante Obispo. Nuevamente la principal iglesia pentecostal de Chile experimentaba una dolorosa separación.

La paradoja de la historia resulta ser que los mismos vicios que se denunciaban, como la falta de transparencia en la contabilidad de los recursos, y la ausencia de un mecanismo claro para regular el tema de la sucesión en el cargo más importante, se replicaron en la naciente congregación de Chávez (Lalive D’Epinay, 1968: Pág. 125).

\section{Años de crecimiento}

A la par de los cambios experimentados por el país, como el aumento de población, el proceso de industrialización, el predominio creciente de las ciudades por sobre los campos como lugares de mayor concentración de habitantes, los años que siguieron a la crisis de 1945, también significaron un crecimiento y una creciente consolidación como la principal minoría religiosa de la Iglesia Metodista Pentecostal. Cabe señalar que las ramas escindidas en 1933 y 1945, también siguieron aumentando la presencia evangélica pentecostal y experimentaron sus propias fracturas en grupos menores. Se sumaron también a la expansión evangélica las misiones pentecostales extranjeras que arribaron a Chile, entre ellas las Asambleas de Dios y la Iglesia del Evangelio Cuadrangular.

A partir de los años 60, Chile entra en una etapa de profundas transformaciones sociopolíticas que culminarán en la crisis de 1973 y la interrupción del sistema democrático hasta 1990. La aproximación del mundo evangélico en general y de la Iglesia Metodista Pentecostal en particular al proceso político chileno, no es materia de este trabajo ${ }^{10}$. Sin embargo, nos remitiremos a

10 Para estudiar la relación entre evangélicos y política, ver: Fontaine T., Arturo y Beyer, Harald, "Retrato del Movimiento Evangélico a la luz de las encuestas de opinión pública", Estudios Públicos, (1991), N 44, Págs. 63-124 Santiago, Centro de Estudios 
señalar que hubo públicas y conocidas diferencias dentro del mundo evangélico chileno para relacionarse con el gobierno militar. Se ha sostenido que en el debate teológico doctrinario evangélico existen dos aproximaciones que estarían en conflicto en cuanto a su interpretación de la relación entre Evangelio y sociedad. Existiría una tendencia ecuménica, generalmente asociada a una valoración de las implicancias socio-políticas del evangelio, y una tendencia fundamentalista, generalmente asociada a actitudes conservadoras en lo social y en lo teológico (Sepúlveda, 1999; Pág. 134). Más allá de que estas tendencias con los cambios ideológicos acaecidos a nivel mundial y local se han ido desdibujando, en la época significó que la Iglesia Metodista Pentecostal adscribiera al sector conservador organizado en torno al Consejo de Pastores y afín al régimen militar, buscando legitimación y el reconocimiento oficial del que habían carecido todos los decenios anteriores. Se organizó en la Catedral de Jotabeche un Te Deum Evangélico paralelo al Te Deum Ecuménico con la asistencia por primera vez de todas las autoridades militares. La otra tendencia de inspiración ecuménica se agrupó en torno a la Confraternidad de Iglesias Cristianas y su posición fue crítica, con especial énfasis en torno a la defensa de los derechos humanos de las personas.

Protagonista principal como pastor de la Iglesia de Jotabeche de los metodistas pentecostales de la época fue Javier Vásquez Valencia.

Públicos; Lagos, Humberto, (1988). Crisis de la Esperanza. Religión y Autoritarismo en Chile, Santiago, Presor-Lar; Ossa, Manuel, (1999). Iglesias Evangélicas y derechos humanos en tiempos de dictadura. La Confraternidad Cristiana de Iglesias. 1981-1989, Santiago, Fundación Konrad Adenauer- Centro Ecuménico Diego de Medellín; Fediakova, Evguenia y Caro, Isaac, "Los Fundamentalismos Religiosos: Etapas y Contexto de Surgimiento", Fermentum, Año 10 (2000) Nº 29, Págs. 453-458 MéridaVenezuela, Revista Venezolana de Sociología y Antropología; Fediakova, Evguenia, "Fundamentalismos Protestantes en Chile y Modernidad", Universium, No 16 (2001), Págs. 77-99 Talca, Universidad de Talca; Fediakova, Evguenia, "Separatismo o Participación: Evangélicos chilenos frente a la política", Revista de Ciencia Política, Volumen XXII (2002), Nº 2, Págs. 32-45/ Santiago, Pontificia Universidad Católica de Chile; Fediakova, Evguenia, "Somos parte de esta sociedad. Evangélicos y Política en el Chile Post Autoritario", Política, (2004), No 43, Págs. 253-284 Santiago, Universidad de Chile. 
El cisma en la iglesia metodista pentecostal de Chile. Una interpretación - Fernando Salas Moncada

Javier Vásquez pastor de Jotabeche desde 1965, sucedió a Mamerto Mancilla Tapia como obispo de la IMP a la muerte de éste en 1982. Mancilla, a su vez había sucedido a Umaña desde 1965. Al pastor Vásquez le correspondió encabezar los Te Deum junto a Pinochet durante todo el gobierno militar. La autoridad, liderazgo y carisma dentro de su congregación eran incuestionables. Desde muy joven experimentó un sentido de misión y destino especial: "Cuando me dirigía a mi habitación para acostarme, fui llevado en éxtasis... separado de este mundo material; fue el Espíritu Santo quien me llevó. Antes yo no sabía de eso. La gente no conoce de estas cosas tan divinas, tan sublimes, tan celestiales. Entonces me acerqué a mi habitación, tal como estoy aquí, y vi el otro lado de la muralla. Con mis ojos no podía ver el otro lado de la muralla, pero con mis ojos del Espíritu, transformados por el éxtasis, fui capaz de ver muchas cosas. Vi todo el universo. Eso me pasó a mí. Mis ojos espirituales se abrieron, pues, con esta visión. Vi a Jesús que venía con sus apóstoles, todos vestidos de blanco, y Jesús traía una corona de Luz, que brillaba como el Sol con toda su fuerza. Se ubicó frente a mi casa y al mirar frente a la calle, lo vi. Entonces el Señor me dijo: Hijo mío, este es el camino correcto; este es el camino que debes seguir para entrar en el Reino de los Cielos. Por esta revelación fui perseguido desde la infancia, y fui a la Cruz del Calvario. Tú serás -me dijo- un predicador de la Revelación. Tú estarás a cargo de un pueblo muy importante; en este momento tú irás por el mundo, dando testimonio de mi nombre. Todo eso me dijo, y de un momento a otro, cuando terminó su mensaje, volví a mi estado físico normal". ${ }^{11}$

En una dimensión más terrenal y mundana, la gestión del Obispo Vázquez Valencia estuvo marcada por la controversia. Desde su apoyo a la dictadura militar hasta acusaciones de corrupción y enriquecimiento ilícito a costa de sus innumerables fieles. ${ }^{12}$

11 Citado en entrevista del autor por Bothner, Matthews S., "El Soplo del Espíritu: Perspectivas sobre el Movimiento Pentecostal en Chile", Estudios Públicos (1994), $\mathrm{N}^{\circ}$ 55, Pág. 286 y 287 / Santiago, Centro de Estudios Públicos, Págs. 261-296.

12 Ver artículos periodísticos aparecidos en "Los Mercaderes del Templo. La Iglesia 
Uno de sus disidentes fue el predicador Mario Vilches quien en 1997 se separa ante la falta de rendición de cuentas y transparencia en el manejo de los recursos de la iglesia. Funda la Iglesia Metodista Pentecostal Universal.

Una vez más las prácticas autoritarias sustentadas en el poder y carisma del líder mantienen un férreo control de la organización.

Al igual que sus antecesores el obispo Vásquez desempeñó su cargo hasta su muerte. Con la diferencia que en vida regularizó estatutariamente su condición de "obispo vitalicio" en una disposición transitoria de los mismos. ${ }^{13}$

En adelante los obispos serán elegidos en una Conferencia Extraordinaria por mayoría absoluta de los miembros presentes y durarán 6 años en el cargo (art. 31 de los Estatutos).

A la muerte del obispo Vázquez ocurrida en el 2003 se desata la pugna por su sucesión, cuyas consecuencias se prolongan hasta la situación actual de quiebre.

\section{Cisma Actual.}

"Al final de cuentas, la raíz de los cismas debe buscarse en la lucha por el poder, y en las rivalidades que oponen a los individuos, más que en el desbordamiento de sus derechos por el jefe carismático" (Lalive D’Epinay, 1968: Pág. 127).

La Iglesia Metodista Pentecostal se constituyó como Corporación de derecho privado en 1929 bajo el número 2148 del registro del Ministerio de Justicia. En el año 2001, en el obispado de Vásquez Valencia y conforme a la nueva Ley de Cultos $N^{\circ}$

Metodista Pentecostal y sus dinastías", El Periodista, Año 2, N ${ }^{\circ} 41$, Edición del domingo 3 de agosto de 2003; "Papito Javier, el pastor que se arrepintió de ser católico. La Historia del líder evangélico más influyente de Chile", Las Últimas Noticias, Edición del domingo 27 de julio de 2003.

13 Ver Estatuto de la IMP Persona jurídica de derecho público, disponible en www. iglesiaimp.com 
El cisma en la iglesia metodista pentecostal de Chile. Una interpretación - Fernando Salas Moncada

19.638, se constituyó como persona jurídica de derecho público. A la muerte del obispo Vásquez acaecida en el 2003 correspondió la elección de un nuevo Obispo conforme a los estatutos, resultando electo Bernardo Cartes Venegas, después de semanas de disputas internas. El obispo Cartes, en opinión de los disidentes actuales, se habría extralimitado en sus atribuciones al conceder unilateralmente un mandato amplio de administración al pastor de la iglesia de Jotabeche sobre todos los bienes de la Corporación de derecho público, contraviniendo expresamente las disposiciones estatutarias que requieren el acuerdo del Presbiterio Mayor, que es organismo colegiado que asesora al obispo en estas materias. El pastor Roberto López junto a otros cinco miembros del Presbiterio Mayor, encabezó la disidencia. Cartes requirió la intervención del Tribunal Eclesiástico a fin de expulsarlos, y de esta manera quedó trabado el conflicto, agravado con acusaciones mutuas ante la justicia ordinaria. En opinión de los disidentes, el obispo Cartes es la cabeza sólo de la persona de derecho público, y no de la corporación de derecho privado que a la fecha del conflicto no había renovado legalmente sus autoridades. En febrero de 2007 se produce la separación de estos dos grupos. El pastor López junto a más de 80 pastores deciden permanecer bajo el alero de la corporación de derecho privado bajo el nombre de Corporación Iglesia Metodista Pentecostal de Chile, celebrando el 11 de Febrero de 2007 elecciones de un nuevo directorio que lo encabeza en calidad de obispo el propio pastor López. El grupo mayoritario celebra elecciones del directorio de la persona jurídica de derecho público Iglesia Metodista Pentecostal de Chile, resultando electo Bernardo Cartes hasta el año 2009.

La denominación evangélica pentecostal más importante de Chile otra vez más repite la constante histórica de división y quiebre en razón de pugnas de poder por el control de la administración y finanzas de la organización.

Desde los años treinta en adelante la acumulación de dinero por concepto de los diezmos en las iglesias más importantes fue 
causa de conflicto. En opinión del teólogo Luis Orellana, miembro de la iglesia en cuestión, no ha existido una real voluntad de crear las condiciones administrativas para un desarrollo armónico de las congregaciones y un uso racional de los recursos, siendo este tema un punto débil y escandaloso del movimiento. "Alli, se encuentra el origen de un sistema de administración financiera individual, falto de ecuanimidad y escasamente cristalino que hasta hoy permanece en las denominaciones más emblemáticas del actual movimiento. Probablemente, ésta sea una de las debilidades más notables del pentecostalismo chileno, lo que se hizo evidente en las etapas posteriores de su historia y donde las divisiones y las luchas internas por el poder han sido recurrentes" (Orellana, 2006: Pág. 154).

\section{Reflexiones finales}

Hemos constatado en este artículo que las causas de las separaciones o quiebres en la historia de la Iglesia Metodista Pentecostal han obedecido a pugnas de poder por el control administrativo y financiero de la organización, más que a cuestiones de tipo doctrinario o teológico. Esta tesis ha sido corroborada por los principales estudiosos del movimiento. Que las pugnas por el poder nacen cuando la dirección superior de la organización no transparenta su gestión y surge un líder con suficiente carisma y autoridad para oponerse. Que luego este líder junto a sus seguidores establece una nueva organización, manteniendo generalmente la misma estructura administrativa y de poder que abandonaron, sin modificar el credo doctrinario y ritual de tipo pentecostal.

En el actual cisma, ambas partes en conflicto demandan jurídicamente el título de herederas originales de la Iglesia Metodista Pentecostal. Una en la esfera del derecho privado y la otra en el ámbito de las personas de derecho público. Pareciera que la pugna por el nombre de la denominación como una "marca registrada" de tipo comercial, fuera más importante que una reflexión profunda acerca de la adscripción a un determinado credo. 
El cisma en la iglesia metodista pentecostal de Chile. Una interpretación - Fernando Salas Moncada

A propósito de la tendencia a la atomización y división de los pentecostales en general, se ha señalado "...en esta situación parece estar operando una combinación de factores teológicos y socioculturales. Entre los primeros se puede mencionar el tradicional énfasis protestante en el libre examen de las Escrituras (libertad de interpretación) y lo que podríamos describir como una débil eclesiología. Sólo la ausencia de profundidad en la comprensión de la iglesia permite comprender por qué algunos líderes de opinión evangélica celebran con entusiasmo la fragmentación institucional como un factor facilitador del crecimiento. Los factores socioculturales se refieren a patrones de organización, de ejercicio de autoridad o de liderazgo, de resolución de conflictos, etc. presentes en la cultura popular local, y que se manifiestan de forma similar en otras organizaciones sociales, sindicales o políticas. Es posible que la propia condición de minoría y los aspectos jurídicos analizados en el capítulo II tengan algo que ver en esta tendencia. Hay iglesias para las cuales la obtención de la persona jurídica es un aspecto más definitorio de su identidad que la referencia a una determinada confesión de fe. Si esto es cierto, se puede prever que un nuevo estatuto jurídico estimulará una búsqueda de mayor solidez institucional" (Sepúlveda, 1999: Pág. 118).

Entre 1992 y el año 2002, conforme al censo de población los habitantes de quince años o más que se declararon evangélicos crecieron de un $12,4 \%$ a un $15,1 \%{ }^{14}$. Cabría suponer que no obstante la dispersión y división de las denominaciones evangélicas, éstas siguen creciendo. Una opinión que ve de manera positiva la fragmentación de las iglesias evangélicas es la de Hermes Canales, recogida por Mario Hoover: "Todos estos movimientos de separación se originan por discrepancias entre los líderes y directivas de las iglesias. La nueva organización llevará el nombre que guardará cierta semejanza con la iglesia madre y el Pastor que la encabeza o representa pondrá todo de su parte, con la ayuda de Dios, para que junto con sus colaboradores esta crezca y se desarrolle en la misma línea doctrinal y costumbres de sus raíces.

14 Ver síntesis de resultados de Censo 2002, disponible en www.ine.cl. 
Estos hechos lejos de debilitar el crecimiento numérico de los fieles, ayudaron al fortalecimiento y crecimiento de las iglesias antiguas y de las nuevas. La constante renovación de métodos para el evangelismo orientados por cada nuevo pastor, ayuda a la expansión de las iglesias a través de todo el país. Cada nuevo desmembramiento produce aires nuevos y frescos y una nueva visión para sus líderes" (Hoover, 2002: Pág. 258).

En nuestra opinión, el crecimiento se ha producido no gracias a la fragmentación, sino a pesar de ella. Entre otras razones, que no es del caso para efectos de este trabajo ahondar, cabría señalar que el éxito de las iglesias evangélicas obedece a la necesidad de la población de una espiritualidad más cercana, una expresión litúrgica más participativa, una presencia de sus pastores y los lugares de culto más próxima.

Ad portas de cumplirse 100 años del nacimiento del movimiento pentecostal autóctono, las iglesias evangélicas en general y la iglesia metodista pentecostal en particular, tienen el desafío y la obligación moral, en razón de representar a la minoría religiosa más importante del país, de constituir un sistema de administración de su organización más transparente y menos autoritario. Que no exista la sospecha de actos de corrupción. Que sus fieles ejerzan los derechos que la Constitución y la nueva Ley de Cultos les garantizan y que se aprovechen los espacios en materia de enseñanza, difusión de sus ideas, asistencia religiosa en hospitales, cárceles y capellanías militares. Que la participación social y política sea estimulada a fin de garantizar la diversidad religiosa en un Estado separado de la Iglesia.

La unidad que experimentó el mundo evangélico a propósito de la tramitación de la Ley de Cultos fue un buen ejemplo de lo que se puede conseguir cuando las disputas de poder ceden a favor de un interés superior. Cuando la defensa de intereses corporativos no sea el único motivo de unión entre los evangélicos y veamos que causas que dicen relación con la dignidad, derechos y espiritualidad de toda la población son sus banderas 
El cisma en la iglesia metodista pentecostal de Chile. Una interpretación - Fernando Salas Moncada

de lucha en cuanto movimiento evangélico general, estaremos en presencia de una comunidad de creyentes plenamente insertos en la sociedad democrática y plural que es Chile hoy, maduros y conscientes de sus obligaciones temporales, y que se han ganado un espacio de respeto y reconocimiento. El lograrlo constituye un desafío permanente.

\section{Bibliografía}

Bothner, Matthew (1994). "El Soplo del Espíritu: Perspectivas sobre el Movimiento Pentecostal en Chile", Estudios Públicos, 55 (invierno 1994)/ Santiago, Centro de Estudios Públicos, Págs. 261-296.

Canut de Bon, Alejandro (1996). Juan Bautista Canut de Bon. El Pastor que dejó un nombre, Santiago, Platero Libros.

Campos Harriet, Fernando (1983). Historia Constitucional de Chile, Santiago, Editorial Jurídica de Chile.

"Declaración Dignitatis Humanae sobre la Libertad Religiosa", Documentos Conciliares Completos, 1967, Madrid, Editorial Razón y Fe.

Fediakova, Evguenia y Caro, Isaac (2000). “Los Fundamentalismos Religiosos: Etapas y Contexto de Surgimiento", Fermentum, Año 10 (2000) Nº 29, Págs. 453-458 / Mérida-Venezuela, Revista Venezolana de Sociología y Antropología.

Fediakova, Evguenia (2001). "Fundamentalismos Protestantes en Chile y Modernidad", Universium, No 16 (2001), Págs. 77-99 / Talca, Universidad de Talca.

Fediakova, Evguenia, "Separatismo o Participación: Evangélicos chilenos frente a la política", Revista de Ciencia Política, Volumen XXII (2002), No 2, Págs. 32-45/ Santiago, Pontificia Universidad Católica de Chile.

(2004). "Somos parte de esta sociedad. Evangélicos y Política en el Chile Post Autoritario", Política, No 43, Págs. 253-284 / Santiago, Universidad de Chile.

Fontaine T., Arturo y Beyer, Harald (1991). "Retrato del Movimiento Evangélico a la luz de las encuestas de opinión pública", Estudios Públicos, N 44, Págs. 63-124 / Santiago, Centro de Estudios Públicos.

Hoover G., Mario (2000). History of the Pentecostal Revival in Chile, Willis Collins Hoover, Santiago, Imprenta Eben-Ezer. 
(2002). El Movimiento Pentecostal en Chile del Siglo XX, Santiago, Imprenta Eben-Ezer.

Lagos, Humberto (1988). Crisis de la Esperanza. Religión y Autoritarismo en Chile, Santiago, Presor-Lar.

Lalive D'Epinay, Christian (1968). El Refugio de las Masas. Estudio Sociológico del Protestantismo Chileno, Santiago, Editorial del Pacífico.

Ley de Culto y documentos complementarios, 1999, Santiago, Instituto Chileno de Estudios Humanísticos y Fundación Konrad Adenauer.

Normas Fundamentales sobre la Libertad de Cultos, 2004, Santiago, Instituto Chileno de Estudios Humanísticos.

Nueva Biblia de Jerusalén, 1975. Bilbao-España, Editorial Desclee de Brouwer.

Orellana U., Luis (2006). El Fuego y la Nieve. Historia del Movimiento Pentecostal en Chile: 1909-1932. Tomo I, Concepción, CEEP Ediciones.

Ossa, Manuel (1999). Iglesias Evangélicas y derechos humanos en tiempos de dictadura. La Confraternidad Cristiana de Iglesias. 1981-1989, Santiago, Fundación Konrad Adenauer-Centro Ecuménico Diego de Medellín.

Pacheco Gómez, Máximo (2004). La separación de la Iglesia y el Estado en Chile y la diplomacia vaticana, Santiago, Editorial Andrés Bello.

Precht Pizarro, Jorge (2001). Derecho Eclesiástico del Estado de Chile, Análisis Históricos y Doctrinales, Santiago, Ediciones Universidad Católica de Chile.

(2006). 15 Estudios sobre Libertad Religiosa en Chile, Santiago, Ediciones Universidad Católica de Chile.

Sepúlveda, Juan (1999). De Peregrinos a Ciudadanos. Breve Historia del Cristianismo Evangélico en Chile, Santiago, Fundación Konrad Adenauer y Facultad Evangélica de Teología.

Synan, Vinson (2006). El siglo del Espíritu Santo, cien años de renuevo pentecostal y carismático, Buenos Aires, Editorial Peniel.

Vergara, Ignacio (1968). El Protestantismo en Chile, Santiago, Editorial del Pacífico. 